\title{
INDEED study: final results of an induction treatment strategy with enfuvirtide in treatment failure patients
} J Reynes*1, I Pellegrin², G Peytavin³ , M Wirden4, B Giffo5 , C Aquilina6,

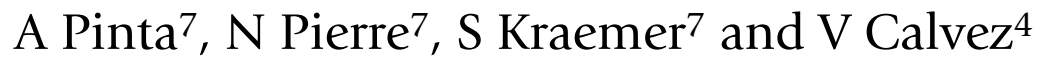

Address: ${ }^{1} \mathrm{CHU}$ de Montpellier, Montpellier, France, ${ }^{2}$ Centre hospitalier Pellegrin, Bordeaux, France, ${ }^{3}$ Hôpital Bichat, Paris, France, ${ }^{4}$ Hôpital Pitié Salpétriêre, Paris, France, ${ }^{5}$ Centre hospitalier de Basse-Terre, Basse-Terre, France, ${ }^{6}$ Hôpital La Grave, Toulouse, France and ${ }^{7}$ Laboratoire Roche, Neuilly-sur-Seine, France

* Corresponding author

from Ninth International Congress on Drug Therapy in HIV Infection Glasgow, UK. 9-13 November 2008

Published: 10 November 2008

Journal of the International AIDS Society 2008, I I (SuppI I):P29 doi: I0.I I86/I758-2652-II-SI-P29

This abstract is available from: http://www.jiasociety.org/content/II/SI/P29

(C) 2008 Reynes et al; licensee BioMed Central Ltd.

\section{Purpose of the study}

To evaluate the efficacy and safety of induction with enfuvirtide (ENF) + antiretroviral (ARV) optimized background $(\mathrm{OB})$ and maintenance with $\mathrm{ENF}+\mathrm{OB}$ vs. dropping ENF in moderate virological failure patients requiring therapeutic change.

\section{Methods}

A prospective, non-inferiority, open-label multicenter trial including patients pretreated with two or three classes of ARV, viral load (VL) = 3 to $5.5 \log 10$ HIV-1 RNA copies/ $\mathrm{ml}$ and possible ARV optimized background with at least two active compounds. Patients were randomized 1:1 between the groups (ENF + OB, OB) after 28 weeks of induction with ENF + OB for patients achieving $\mathrm{VL}<400$ copies/ml at week 16, and VL<50 copies/ml at week 24 . The primary end-point was proportion of patients with $\mathrm{VL}<50$ copies/ml at week 52 .

\section{Summary of results}

84 patients included (37 centers), $80 \%$ male, $33 \%$ with AIDS. Mean duration of previous ARV treatment $=10+/-$ 4 years. At inclusion, median $\mathrm{VL}=4.3 \log 10$ copies $/ \mathrm{ml}$, median CD4 $=259$ cells/mm3 (<200 CD4/mm3: 32\%). Number of fully active ARV in the OB (GSS) was $=2$ for $74 \%$ of patients (according to genotypic resistance test performed at selection combined with all previous selected mutations). At week 4 , a reduction of $\mathrm{VL}>1 \log 10$ was observed in $92 \%$ of patients and a reduction of $\mathrm{VL}>2$ $\log 10$ vas obtained in $42 \%$ ( $74 \%$ in patients with $\mathrm{VL}=$ 30,000 copies $/ \mathrm{ml}$ at inclusion). Median reduction of $\mathrm{VL}$ at week 4 and week 24 were $1,9 \log 10$ and 2,3 $\log 10$, respectively. Adequate ENF concentrations $(>1,000 \mathrm{ng} / \mathrm{ml})$ were observed in $80 \%$ of patients at week 4 . At week $24,69 \%$ of patients reached $\mathrm{VL}<50$ copies $/ \mathrm{ml}$ regardless of GSS. Median increase from baseline in CD 4 cells at week 4 and week 24 were $25 / \mathrm{mm} 3$ and $71 / \mathrm{mm} 3$, respectively. At week 52 within 45 randomized patients, 67\% (16/24) in the ENF + OB arm and 57\% (12/21) in the OB arm achieved $\mathrm{VL}<50$ copies/ml without failure after randomization. Median increase in CD4 from week 28 to week 52 were $+18 / \mathrm{mm} 3$ in ENF + OB arm and $-9 / \mathrm{mm} 3$ in OB arm. $56 \%$ of patients presented at least one injection site reaction (ISR) with no influence observed of $\mathrm{CD} 4$ count, $\mathrm{VL}$, or lipodystrophy.

\section{Conclusion}

Addition of ENF to OB led to fast and good virological response (at least 2 log drop in VL observed in $74 \%$ of patients with initial VL $>30,000$ copies/ml at week 4). During maintenance phase, in this population with a smaller than planned number of patients, we cannot conclude as to the non-inferiority of OB vs. ENF + OB at week 52. 